\title{
Acromegaly presenting with diabetic ketoacidosis
}

\author{
JR Katz, R Edwards, M Khan, GS Conway
}

Summary

Diabetes in acromegaly is usually noninsulin dependent and is secondary to insulin resistance caused by growth hormone excess. Diabetic ketoacidosis is a result of relative insulin deficiency and is a rare feature of acromegaly. We describe a case of acromegaly presenting with diabetic ketoacidosis. We demonstrate that growth hormone excess can cause diabetic ketoacidosis in the presence of relative, but not absolute insulin deficiency.

Keywords: acromegaly, diabetic ketoacidosis, insulin resistance

A 40-year-old man was admitted as an emergency with a one-month history of thirst, polyuria and weight loss of $7 \mathrm{~kg}$. On direct questioning, the patient admitted to an increase in the size of his head, hands and feet over the last year. Friends had recently failed to recognise him. On examination, he was clearly acromegalic, severely dehydrated and exhibiting Kussmaul's respiration. Investigations revealed $3+$ ketonuria on urinalysis. Blood glucose was $29.1 \mathrm{mmol} / \mathrm{l}$, plasma bicarbonate $7 \mathrm{mmol} / \mathrm{l}$, sodium $132 \mathrm{mmol} / \mathrm{l}$, potassium 3.7 $\mathrm{mmol} / \mathrm{l}$, glycosylated haemoglobin (HbA1) $15.0 \%$. Arterial blood gases $\mathrm{pH} 7.10, \mathrm{pCO}_{2}$ $1.0 \mathrm{kPa}$, base excess $27 \mathrm{mmol} / \mathrm{l}$.

Following the diagnosis of diabetic ketoacidosis, he was treated with an intravenous insulin infusion and fluids containing potassium supplements. Satisfactory diabetic control was achieved with 52 units of Human Mixtard insulin 30 ge daily, given subcutaneously in divided doses. The diagnosis of acromegaly was confirmed by the finding of a raised basal growth hormone level of $37.1 \mathrm{mU} /$ 1 , increasing after a 75-g oral glucose load to $>120 \mathrm{mU} / \mathrm{l}$ at 30 minutes and $66.2 \mathrm{mU} / \mathrm{l}$ at 120 minutes. The corresponding glucose and insulin measurements are shown in the figure and show significant levels of insulin but a flat response to the glucose load.

There was evidence of hypogonadotrophic hypogonadism (luteinising hormone $<1.0 \mathrm{IU} / 1$, follicle-stimulating hormone $2.7 \mathrm{IU} / 1$, testosterone $1.7 \mathrm{nmol} / \mathrm{l}$ ), but levels of thyroidstimulating hormone $(0.9 \mathrm{mU} / \mathrm{l})$, prolactin (125 mU/l) and cortisol (398 nmol/1 at 09.00 h) were normal. Magnetic resonance imaging (MRI) of the pituitary showed an enlarged fossa containing a left-sided pituitary macroadenoma with suprasellar extension, displacing the ipsilateral cavernous sinus and internal carotid artery laterally. The visual fields were normal.
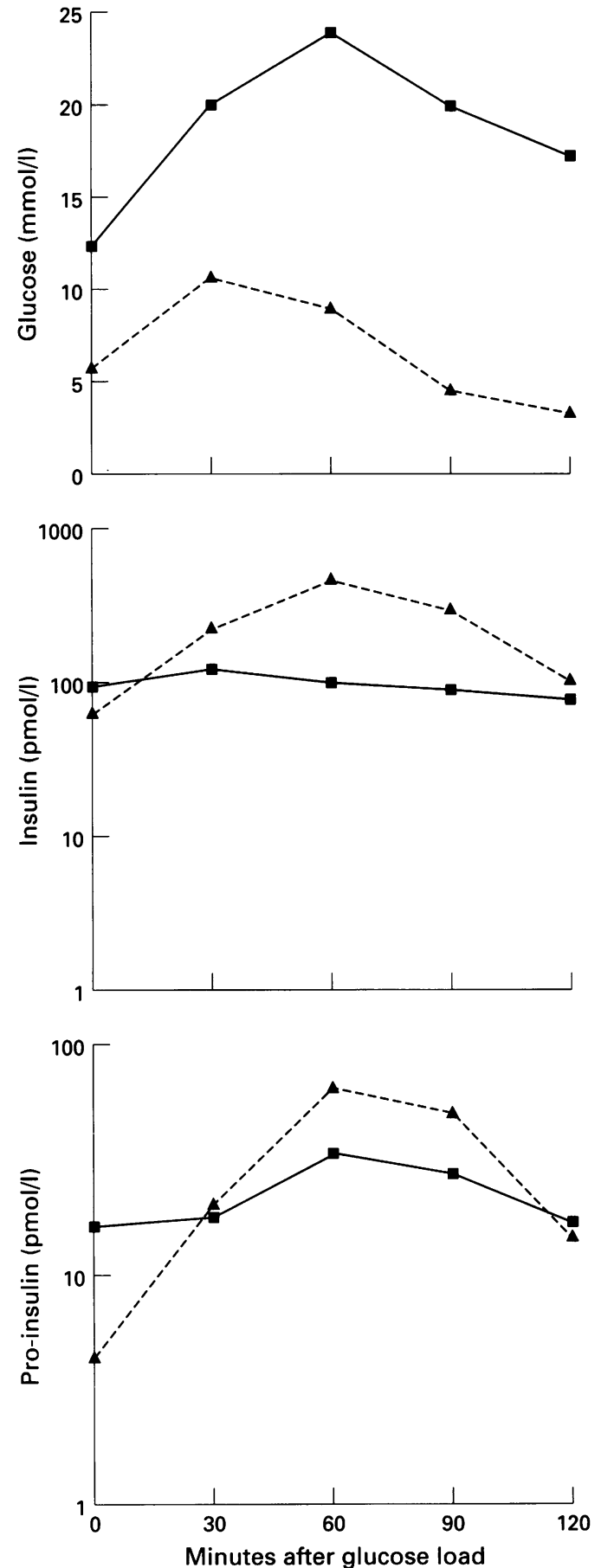

Figure Glucose, insulin and proinsulin responses to an oral 75-g glucose load. Measurements of insulin, proinsulin and glucose at baseline and 30, 60,90 and 120 minutes after glucose administration. See text for growth hormone values. Solid line: pre-operative assessment; broken line: post-operative assessment. Plasma glucose measured by glucose oxidase assay. Insulin and proinsulin measured by specific two-site immunoassay (Novo Nordisk) 
Trans-sphenoidal surgery was carried out three weeks after initial presentation and postoperatively the patient was given 14 units of Human Mixtard insulin and $30 \mathrm{mg}$ of hydrocortisone daily. Insulin and hydrocortisone were stopped six weeks after surgery. Eight weeks post-operatively, he had a further oral glucose tolerance test with a normal glucose and insulin profile (figure); the basal growth hormone level of $2.7 \mathrm{mU} / 1$ suppressed to 1.4 $\mathrm{mU} / 1$ at 30 minutes and $<1.5 \mathrm{mU} / 1$ at 120 minutes. The hypogonadotrophic hypogonadism had resolved (luteinising hormone $4.3 \mathrm{IU} /$ 1 , follicle-stimulating hormone $6.4 \mathrm{IU} / 1$, testosterone $19.2 \mathrm{nmol} / \mathrm{l})$. The thyroid-stimulating hormone, prolactin and $09.00 \mathrm{~h}$ cortisol levels remained normal post-operatively.

\section{Discussion}

Diabetic ketoacidosis is a rare but recognised finding in advanced cases of acromegaly. ${ }^{1,2}$ The initial presentation of an acromegalic patient with diabetic ketoacidosis has not been described previously. Symptomatic non-insulin dependent diabetes was the presenting feature in $6 \%$ of acromegalics in one of the largest retrospective analyses to date. ${ }^{3}$ Diabetic ketoacidosis develops when there is an absolute or relative deficiency of insulin and an excess of counter-regulatory hormones (cortisol, catecholamines, glucagon or growth hormone). ${ }^{4}$ Diabetic ketoacidosis in the presence of normal circulating levels of insulin has been described previously, ${ }^{5}$ but a normal insulin level is inappropriately low in the presence of hyperglycaemia. It has been suggested that elevated levels of counter-regulatory hormones lead to the development of ketoacidosis in these

1 Coggeshall C, Root HF. Acromegaly and diabetes mellitus. Endocrinology 1940; 26: 1-25.

2 Abrahamson MJ. Death from diabetic ketoacidosis after cessation of octreotide in acromegaly. Lancet 1990; 336: 318-9.

3 Nabarro JDN. Acromegaly. Clin Endocrinol 1987; 26: 481512.

4 Marshall SM, Walker M, Alberti KGMM. Diabetic ketoacidosis and hyperglycaemic non-ketotic coma. In: Alberti KGMM, ed, International textbook of diabetes mellitus. Chichester: John Wiley, 1992; pp 1151-64.

\section{Summary points}

- diabetes in acromegaly is well described but diabetic ketoacidosis is rare

- diabetic ketoacidosis as a presenting feature of acromegaly has not been described prior to this report

- diabetic ketoacidosis may develop despite the presence of insulin if counter-regulatory hormone levels are excessive

- successful treatment of acromegaly results in improved glucose tolerance with cure of diabetes in many cases

patients. ${ }^{4,5}$ In the case presented here, diabetic ketoacidosis resulted from excessive growth hormone levels in the presence of relative insulin deficiency. Insulin resistance, described previously in acromegaly, ${ }^{6,7}$ whether mediated directly by growth hormone or indirectly via IGF-1, contributed to the development of glucose intolerance and subsequent ketoacidosis.

Treatment of acromegaly results in an improvement in glucose tolerance in the majority, with cure of diabetes in many cases. Nabarro described a rapid reduction in insulin requirement in insulin-dependent diabetics following cure of their acromegaly. ${ }^{3}$ In a proportion of these cases, the glucose tolerance test normalised after 6-12 months. In this case study, the glucose tolerance and insulin response to a glucose load normalised only six weeks after trans-sphenoidal surgery. This case demonstrates both a unique presentation of acromegaly and an unusually rapid cure of diabetes following surgical resection of the pituitary tumour.

5 Schade DS, Eaton RP. Pathogenesis of diabetic ketoacido-

6 Lerario AC, El-AndereW, Wajchenberg BL, Ohnuma LY, Rocha MH, Andriolo A. Insulin resistance in acromegal: evaluation by studies of insulin binding to erythrocytes. $\mathcal{f}$ Endocrinol Invest 1989; 12: 155-61.

7 Hansen I, Tsalikian E, Beaufrere B, Gerich J, Hymond M, RizzaR. Insulin resistance in acromegaly: defects in both hepatic and extra-hepatic insulin action. Am f Physiol 1986; 250: 269-73. 